Article

\title{
Alkylation of Aromatic Compounds with Pentabromobenzyl Bromide and Tetrabromoxylene Dibromide as a New Route to High Molecular Weight Brominated Flame Retardants
}

\author{
Mark Gelmont ${ }^{1}$, Michael Yuzefovitch ${ }^{1}$, David Yoffe ${ }^{1}$, Eyal Eden ${ }^{2}$ and Sergei Levchik ${ }^{3, *}$ \\ 1 IMI Institute for R\&D, Haifa Road, Industrial Zone Kiryat Ata, Haifa Bay 28226, Israel; \\ mark.gelmont@icl-group.com (M.G.); michael.yuzefovitch@icl-group.com (M.Y.); \\ david.yoffe@icl-group.com (D.Y.) \\ 2 ICL-IP, P.O. Box 180, Beer Sheva 84101, Israel; eyal.eden@icl-group.com \\ 3 ICL-IP America, 769 Old Saw Mill River Rd, Tarrytown, NY 10591, USA \\ * Correspondence: sergei.levchik@icl-group.com
}

Received: 6 December 2019; Accepted: 19 January 2020; Published: 6 February 2020

\begin{abstract}
In the view of many national and international human health and environmental regulations, polymeric flame retardants are sustainable products. In this work, a series of high molecular weight and polymeric brominated flame retardants are synthesized by the alkylation of aromatic molecules or the alkylation of aromatic polymers with pentabromobenzyl bromide (PBBB) or tetrabromoxylylene dibromide (TBXDB). The flame retardants prepared via the alkylation of toluene or diphenylethane with PBBB were found to be not truly polymeric but had high $M_{\mathrm{W}}>1400$. However, the alkylation of the same aromatic molecules by a mixture of PBBB and TBXDP resulted in polymeric flame retardants with $M_{\mathrm{w}}>130,000$. Two other polymeric flame retardants were prepared by the alkylation of aromatic polymers (polyphenylene ether or polystyrene) with PBBB. It was found that the new flame retardants had a high bromine content of more than $68 \%$. They showed high thermal stability with the onset of thermal decomposition above $360{ }^{\circ} \mathrm{C}$ and a maximum rate of weight loss at about $375-410^{\circ} \mathrm{C}$. The newly synthesized flame retardants were tested in different thermoplastics. Flame retardant efficiency and physical properties were comparable or better than the reference commercial flame retardants.
\end{abstract}

Keywords: flame retardant; pentabromobenzyl bromide; tetrabromoxylylene dibromide; polypropylene; polyamide 6.6; HIPS; ABS

\section{Introduction}

Because a bromine atom is heavy, brominated flame retardants (FRs) have larger molecular weight (typically $>700 \mathrm{~g} /$ mole) compared to other types of organic flame retardants. From a regulatory point of view molecules consisting of at least three repeating units and having molecular weight $>1500$ are recognized as polymers in most geographical areas. Polymeric flame retardants have a few obvious technical, environmental, and toxicological benefits. However, it is important to note that there are some brominated flame retardants with molecular weight $>1500 \mathrm{~g} / \mathrm{mole}$ that formally cannot be called polymers because they are not built with repeating units.

Due to the nature of biological membranes very large molecules cannot pass through them. This phenomenon is well known in pharmacology as the "Liminski Rule of Five" which is used to predict biological activity of chemicals based on molecular weight and lipophilicity [1]. The rule suggests that chemicals with molecular weight $>500 \mathrm{~g} /$ mole exhibit poor permeation of cell membranes. 
Thus, the membranes of the skin, lungs, and gastrointestinal tract typically do not allow large molecules to pass through. If large molecular weight brominated FR is ingested, it is usually excreted without being substantially absorbed into the body [2]. Because of this polymeric and large non-polymeric molecules avoid the problem of several types of lower molecular weight brominated flame retardants that are the subject of restrictions in use [3].

Polymeric FRs typically have low solubility in water, which means that once incorporated into the end-product plastic matrix, they become integrated with the plastic and leaching is unlikely to occur. Because of negligible vapor pressure they do not migrate to the surface of the plastic during aging, thus significantly diminishing or eliminating any potential blooming in the finished product. Extensive testing has also shown that formation of polybrominated p-dibenzodioxins and dibenzofurans can be controlled by proper incineration of thermoplastics containing polymeric brominated FRs $[4,5]$. It has also been found that thermoplastics containing polymeric brominated FRs show high thermal stability and allow good physical properties of re-processed polymers in mechanical recycling operations to be maintained [6-9]. This is a very important consideration from an environmental viewpoint.

For many years the flame retardant industry has produced a series of polymeric brominated flame retardants. The most common are brominated polystyrene, which is predominantly used in polyamides; brominated polycarbonate and poly(pentabromobenzyl acrylate), which are mostly used in thermoplastic polyesters; and brominated epoxy polymers, which have a wide range of applications from styrenic thermoplastics to engineering resins [10]. A most recent addition to the family is brominated styrene-butadiene-styrene block copolymer [11] (only the butadiene part is brominated) which finds application in polystyrene foam insulation [12]. Because compatibility (miscibility) of polymers depends very much on polymer structure and molecular weight, the industry is actively searching for new brominated flame retardants [13-17] which are sustainable and can replace traditional non-polymeric counterparts.

In this paper, we synthesize new compounds containing pentabromobenzyl moieties. These compounds are prepared by electrophilic C-alkylation of different aromatic compounds with pentabromobenzyl bromide (PBBB) in the presence of Friedel-Crafts catalysts. The pentabromobenzyl-group-containing compounds have a high molecular weight $(>1000)$ and a high bromine content (not less than $70 \%$ ). They are insoluble in water, stable against hydrolysis, and show very high thermal stability. Using a similar synthetic route, we also perform C-alkylation using difunctional tetrabromoxylylene dibromide (TBXDB), which results in polymeric products. The alkylation with both PBBB and TBXDB leads to high bromine content polymeric products with pentabromobenzyl pendant groups. Finally, we alkylate polyphenylene ether (PPE) and polystyrene (PS) with PBBB. Because PPE is an oligomeric and PS is a polymeric precursor, the obtained brominated flame retardants are polymers as well.

\section{Materials and Methods}

\subsection{Materials}

Technical grade bromine from ICL-IP (Beer Sheva, Israel) was used for the bromination. Toluene and xylene were purchased from Bio-Lab Chemicals (Jerusalem, Israel). Pentabromobenzyl bromide (PBBB) was prepared according to the known method described in the patent literature $[18,19]$. In short, toluene was first reacted with elemental bromine in the presence of an $\mathrm{AlCl}_{3}$ catalyst and using dibromomethane as a solvent, which resulted in the bromination of the aromatic ring. In the second step, the methyl group was brominated using elemental bromine and AIBN as a free radical initiator. TBXDB was prepared by a similar synthesis route. Diphenylethane used in further alkylation reactions was provided by Bailly (Taizhou, China). Polyphenylene ether (Santovac 7) of molecular weight $\left(M_{\mathrm{W}}\right) \sim 450$ corresponding to about five phenyl units was purchased from Santolubes LLC. (Spartanburg, SC, USA) Polystyrene $M_{\mathrm{W}}=170,000$ was supplied by Arkema (Colombes, France). 


\subsection{Chemical Analysis}

The bromine content of the new flame retardants was measured by the Parr Bomb method. The sample ( 0.08-0.12 g) was placed in a peroxide bomb vessel, after which $0.5 \mathrm{~g}$ of sucrose was added; finally, a full dipper of sodium peroxide was added. The bottom of the bomb was heated up to about $200{ }^{\circ} \mathrm{C}$ with a Bunsen burner so that the sample was fully oxidized by sodium peroxide. Then, the bomb was cooled down and the residual pressure was released. Bromine mostly in the form of sodium bromide was retained in the bomb. The content of the bomb was then combined with warm water and hydrazine sulfate was added to destroy residual sodium peroxide. Nitric acid was added in portions until the solution became slightly acidic. The solution was cooled down and titrated with $\mathrm{AgNO}_{3}(0.1 \mathrm{~N})$ to determine bromine content.

\subsection{Gel Permeation Chromatography (GPC)}

The molecular weight of the new polymeric flame retardants was measured using a Viscotek HT-GPC 350A module (Malvern Instruments, Malvern, UK) equipped with an RI, viscometer, and light scattering detectors. Two Tosoh TSK-GEL GMHhr-H(S) HT $7.8 \mathrm{~mm} \times 30.0 \mathrm{~cm}, 13 \mu \mathrm{m}$ GPC columns were used. The samples were dissolved in 1,2,4-trichlorobenzene and stabilized with 2,6-di-tert-butyl-4-methyl-phenol (BHT). The flow rate was set to $1.0 \mathrm{~mL} / \mathrm{min}$ and the temperature of both the detector and column was set to $120^{\circ} \mathrm{C}$. Calibration was done using a Malvern TDS2000 (HT-TDS-PS) polystyrene standards kit.

\subsection{Infrared Spectroscopy (FTIR)}

Infrared spectra of new flame retardants were collected on a Bruker Tensor II FTIR instrument (Billerica, MA, USA) using the ATR technique.

\subsection{Thermal Analysis}

TGA analysis was performed using TGA Q500, TA Instruments (New Castle, DE, USA). Samples of $\sim 10 \mathrm{mg}$ were heated in an aluminum oxide crucible from 35 to about $700{ }^{\circ} \mathrm{C}$ with a heating rate of $10^{\circ} \mathrm{C} / \mathrm{min}$ in a nitrogen atmosphere.

\subsection{Ingredients, Compounding, and Molding}

Polymers and other components of the flame retardant compositions are listed in Table 1. A Berstorff ZE25 co-rotating twin screw extruder (KraussMaffei Berstoff, Hanover, Germany) with $\mathrm{L} / \mathrm{D}=32$ was used to compound the newly synthesized flame retardants in different polymers. Commercial flame retardant additives listed in Table 1 were used as benchmarks in different polymers. Polypropylene, high-impact polystyrene (HIPS) and acrylonitrile-butadiene-styrene copolymer (ABS) were used as received whereas polyamide (PA) 6.6 was dried in a vacuum oven at $80^{\circ} \mathrm{C}$ overnight before extrusion. The polymer, the flame retardants, and all other ingredients were thoroughly mixed in a plastic bag and fed into the main port using a volumetric feeder. In the case of PA 6.6 glass fibers were fed into heating zone 3 using the side feeder. Polypropylene was extruded at $160-230^{\circ} \mathrm{C}$, HIPS at $180-220^{\circ} \mathrm{C}$, ABS at $180-240{ }^{\circ} \mathrm{C}$, and PA 6.6 at $250-280^{\circ} \mathrm{C}$. The strands produced in the extruder were cooled under water and pelletized using an Accrapak System 750/3 pelletizer (Accrapak Sytems, Warrington, UK). Obtained pellets were dried in a circulating air oven at $80^{\circ} \mathrm{C}$ for at least $3 \mathrm{~h}$ before they were injection molded into the test specimens using an Allrounder 500-150 molding machine (Arburg, Lossburg, Germany). The test specimen $1.6 \mathrm{~mm}$ standard UL-94 bars and standard "dog-bone" bars for physical testing were conditioned at $23^{\circ} \mathrm{C}$ for one week before testing. 
Table 1. Polymers, reference flame retardants, synergists, fillers, stabilizers, and processing aids used in preparation of the flame-retardant plastics.

\begin{tabular}{|c|c|c|}
\hline Component & Trade Name and Manufacture & Function \\
\hline Impact-modified polypropylene (PP) & Capilene ${ }^{\circledR}$ SL-50 (Caol) & Polymer matrix \\
\hline $\begin{array}{l}\text { Polyamide } 6.6 \text { (contains nucleating agent, } \\
\text { mold release agent, and lubricant) (PA 6.6) }\end{array}$ & Aculon ${ }^{\circledR}$ S 223D (DSM) & Polymer matrix \\
\hline High-impact polystyrene (HIPS) & Styron $^{\mathrm{TM}} 1200$ (Dow) & Polymer matrix \\
\hline Acrylonitrile-butadiene-styrene copolymer (ABS) & ABS Magnum ${ }^{\mathrm{TM}} 3404$ (Styron) & Polymer matrix \\
\hline Decabromodiphenylethane & FR-1410 (ICL-IP) & $\begin{array}{l}\text { Reference flame } \\
\text { retardant }\end{array}$ \\
\hline Poly(pentabromobenzyl acrylate) & FR-1025 (ICL-IP) & $\begin{array}{l}\text { Reference flame } \\
\text { retardant }\end{array}$ \\
\hline Brominated epoxy polymer & F-3014 (ICL-IP) & $\begin{array}{l}\text { Reference flame } \\
\text { retardant }\end{array}$ \\
\hline $\begin{array}{l}\text { Tribromophenol-end-capped brominated } \\
\text { epoxy polymer }\end{array}$ & F-3020 (ICL-IP) & $\begin{array}{l}\text { Reference flame } \\
\text { retardant }\end{array}$ \\
\hline Brominated polystyrene & FR-803P (ICL-IP) & $\begin{array}{l}\text { Reference flame } \\
\text { retardant }\end{array}$ \\
\hline $\begin{array}{l}\text { Antimony trioxide masterbatch (MB) containing } \\
80 \text { wt. } \% \mathrm{Sb}_{2} \mathrm{O}_{3}\end{array}$ & FR00112 (Kafrit) & $\begin{array}{l}\text { Flame retardant (FR) } \\
\text { synergist }\end{array}$ \\
\hline Polytetrafluoroethylene (PTFE) & Hostaflon ${ }^{\circledR} 2017$ (Dyneon) & Anti-dripping agent \\
\hline Styrene-butadiene-styrene block copolymer (SBS) & SBS 501S (LG Chem) & Impact modifier \\
\hline Talc & Lotalc & Filler \\
\hline Masterbatch of talc, 60 wt. $\%$ & Talc MB (Kafrit) & Filler \\
\hline Glass fibers & GF ChopVantage $^{\circledR} 3660$ (PPG) & Filler \\
\hline $\begin{array}{l}\text { Blend of tris(2,4-ditert-butylphenyl)phosphite } \\
\text { and pentaerythritol tetrakis [3-[3,5-di-tert-butyl-4 } \\
\text {-hydroxyphenyl]propionate] (50:50) }\end{array}$ & Irganox ${ }^{\circledR}$ B 225 (BASF) & $\begin{array}{l}\text { Antioxidant and heat } \\
\text { stabilizer }\end{array}$ \\
\hline Multifunctional nitrogen-containing hindered phenol & Acrawax ${ }^{\circledR} \mathrm{C}$ (Lonza) & $\begin{array}{l}\text { Antioxidant and heat } \\
\text { stabilizer }\end{array}$ \\
\hline$N, N^{\prime}$ ethylene bis stearamide & Irganox ${ }^{\circledR}$ B1171 (BASF) & Lubricant \\
\hline Calcium stearate & Ca-stearate & Lubricant \\
\hline
\end{tabular}

\subsection{Flammability Test}

A flammability test was carried out according to the Underwriters-Laboratories standard UL-94, applying a vertical Bunsen burner to the standard specimens of $1.6 \mathrm{~mm}$ thickness for polypropylene, ABS, and HIPS and $0.8 \mathrm{~mm}$ for glass-filled PA 6.6.

\subsection{Mechanical Properties}

Izod notched impact strength was measured using a CEAST 9050 Pendulum Impact System (Instron, Norwood, MA, USA) following the ASTM D-256 protocol. Tensile properties (tensile strength, tensile modulus, and elongation at break) were measured using a Z010 Material Tester (Zwick Roell, Ulm, Germany) according to ASTM D-638 at a $5 \mathrm{~mm} / \mathrm{min}$ speed of clamp using type 2 dumbbells.

\subsection{Heat Distortion Temperature (HDT)}

HDT was measured according to ASTM D648 at a heating rate of $2{ }^{\circ} \mathrm{C} / \mathrm{min}$ and a $1820 \mathrm{KPa}$ cell load using a HDT/Vicat-Plus (Lloyd Instruments, West Sussex, UK). 


\subsection{Melt Flow Index (MFI)}

MFI was determined according to ASTM D1238 using a Meltflixer 2000 melt flow instrument (Thermo Hake, Karlsruhe, Germany) with a cell load of $2.16 \mathrm{~kg}$. A temperature of $230^{\circ} \mathrm{C}$ was used for polypropylene, HIPS, and ABS and $250{ }^{\circ} \mathrm{C}$ for PA 6.6.

\subsection{Synthesis}

\subsubsection{Alkylation of Toluene with PBBB (T-PBBB)}

Dibromomethane (200 mL), PBBB $(62.2 \mathrm{~g}, 0.11 \mathrm{~mol})$, and toluene $(3.7 \mathrm{~g}, 0.04 \mathrm{~mol})$ were placed into a $500 \mathrm{~mL}$ flask fitted with a mechanical stirrer, thermometer, condenser and $\mathrm{N}_{2}$ inlet. The mixture was heated to $70{ }^{\circ} \mathrm{C}$ until the PBBB was dissolved. $\mathrm{AlCl}_{3}(0.7 \mathrm{~g}, 0.005 \mathrm{~mol})$ was added and the vigorous formation of $\mathrm{HBr}$ was started. The mixture was heated at $80^{\circ} \mathrm{C}$ for $6 \mathrm{~h}$ until the PBBB disappeared (controlled by GC). The reaction mixture was washed three times with water $(3 \times 120 \mathrm{~mL})$ and sodium bisulfite (1.5 mL, $28 \%$ aqueous solution), with 20 min taken for each washing. After that, the solid was filtered out and re-slurried with dichloromethane $(2 \times 200 \mathrm{~mL})$ at $40{ }^{\circ} \mathrm{C}$ for one hour (each re-slurry). The reaction mixture was cooled to $20^{\circ} \mathrm{C}$ and the solid was filtered off and dried in an oven at $150{ }^{\circ} \mathrm{C}$ under reduced pressure for $24 \mathrm{~h}$ to give $42.7 \mathrm{~g}$, corresponding to an $\sim 75 \%$ yield, based on PBBB. According to the elemental analysis, the content of bromine was about $76 \%$, corresponding to $\sim 2.7$ PBBB units per one molecule of toluene. The estimated molecular weight was about 1400 . The FTIR spectrum of T-PBBB is shown in Figure 1. The major absorption bands attributed to the pentabromobenzene ring are $1316 \mathrm{~cm}^{-1}$ (semicircle stretching), $1060 \mathrm{~cm}^{-1}$ (C-Br stretching), and $552 \mathrm{~cm}^{-1}$ (ring bending) [20]. The bands at $2980 \mathrm{~cm}^{-1}\left(\mathrm{CH}_{3}\right.$ stretching), $1431 \mathrm{~cm}^{-1}$ (semicircle stretching) and $947 \mathrm{~cm}^{-1}$ (aromatic $\mathrm{C}-\mathrm{H}$ bending) can be assigned to substituted toluene. Solubility in organic solvents of P-PBBB was very poor, which did not allow for the performing of NMR analysis. The chemical structure of P-PBBB can be represented as follows.
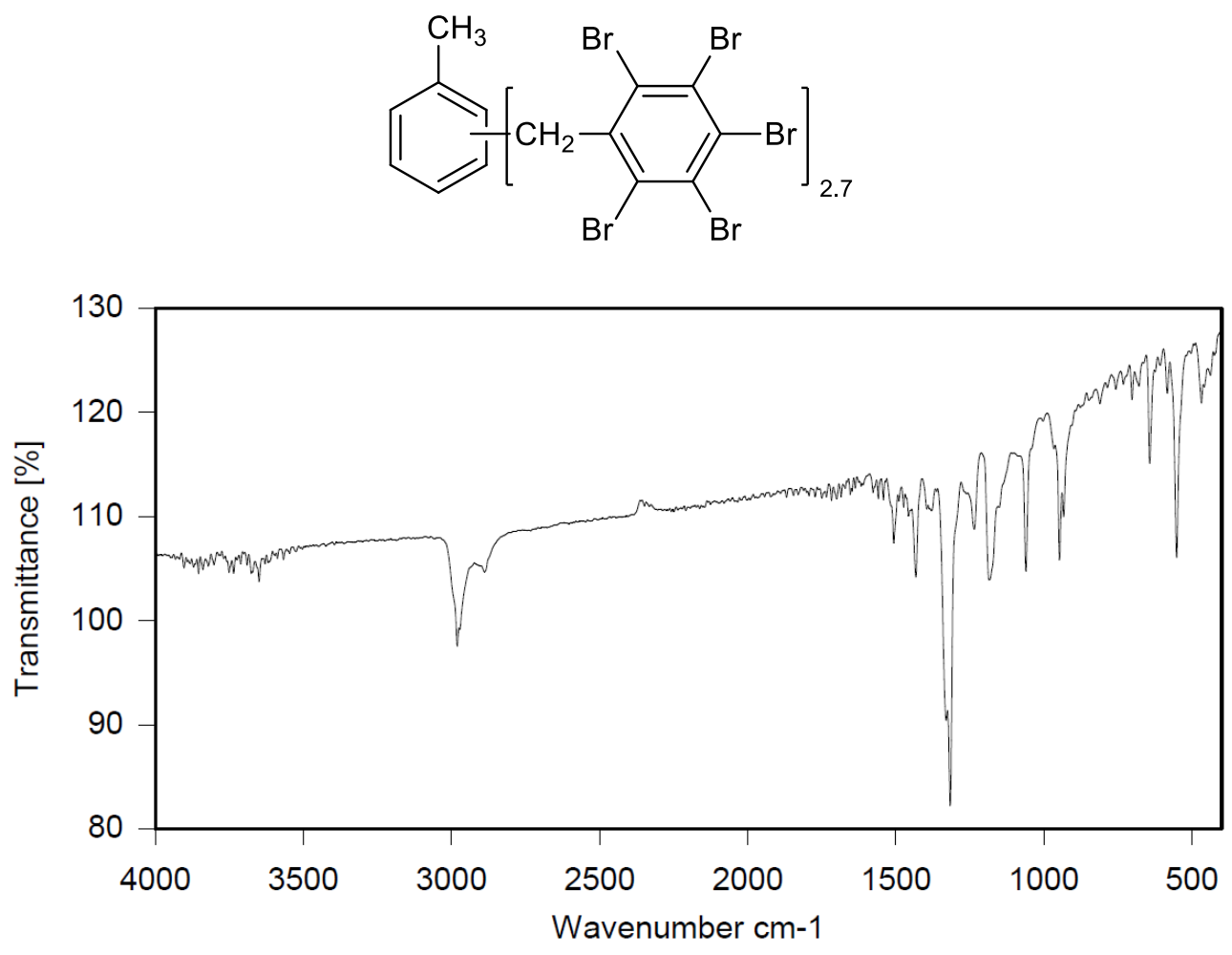

Figure 1. FTIR spectrum of toluene alkylated with entabromobenzyl bromide (T-PBBB). 


\subsubsection{Alkylation of Diphenylethane with PBBB (DPE-PBBB)}

Dichloroethane (1600 mL), PBBB (805.6 g, $1.42 \mathrm{~mol})$ and diphenylethane $(57.70 \mathrm{~g}, 0.317 \mathrm{~mol})$ were placed into a $2000 \mathrm{~mL}$ glass reactor fitted with a mechanical stirrer, thermometer, condenser, and $\mathrm{N}_{2}$ inlet. The mixture was heated to $70{ }^{\circ} \mathrm{C}$ and $\mathrm{AlCl}_{3}(4.5 \mathrm{~g}, 0.17 \mathrm{~mol})$ was added portion wise over $\sim 3 \mathrm{~h}$. Then, the mixture was heated for an additional hour at $65-75^{\circ} \mathrm{C}$ until the PBBB disappeared (by GC). The reaction mixture was washed three times with water $(3 \times 1000 \mathrm{~mL})$ at $\sim 60^{\circ} \mathrm{C}$ and sodium bisulfite (20 mL, 28\% aqueous solution), with $20 \mathrm{~min}$ taken for each washing. After this, the solid was filtered off at $40-50{ }^{\circ} \mathrm{C}$, washed with $200 \mathrm{~mL}$ dichloroethane, and dried in an oven at $150{ }^{\circ} \mathrm{C}$ under reduced pressure for $20 \mathrm{~h}$ to give $738 \mathrm{~g}$, corresponding to an $\sim 98 \%$ yield. The content of bromine was $\sim 75 \%$. The product contained on average five PBBB units and had a $M_{\mathrm{W}}$ of about 2600 . The FTIR spectrum of DPE-PBBB is shown in Figure 2. The major absorption bands attributed to the pentabromobenzene ring are $1317 \mathrm{~cm}^{-1}$ (semicircle stretching), $1061 \mathrm{~cm}^{-1}$ (C-Br stretching) and $552 \mathrm{~cm}^{-1}$ (ring bending). The bands at $1491 \mathrm{~cm}^{-1}$ and $1431 \mathrm{~cm}^{-1}$ (semicircle stretching) and $942 \mathrm{~cm}^{-1}$ (aromatic C-H bending) can be assigned to substituted diphenylethane. Solubility in organic solvents of DPE-PBBB was very poor, which did not allow for the performing of NMR analysis. The chemical structure of DPE-PBBB can be represented as follows.


Figure 2. FTIR spectrum of diphenylethane alkylated with PBBB (DPE-PBBB).

\subsubsection{Alkylation of Toluene with PBBB and TBXDB (T-PBBB-TBXDB)}

Dichloroethane (300 mL), PBBB (84.8 g, $0.15 \mathrm{~mol})$, TBXDB ( $66.1 \mathrm{~g}, 0.114 \mathrm{~mol})$, and toluene (13.8 g, $0.15 \mathrm{~mol}$ ) were placed in a $500 \mathrm{~mL}$ reactor fitted with a mechanical stirrer, thermometer, condenser, $\mathrm{HBr}$ trap, and $\mathrm{N}_{2}$ inlet. The mixture was heated to $60{ }^{\circ} \mathrm{C}$. $\mathrm{AlCl}_{3}(1.3 \mathrm{~g}, 0.01 \mathrm{~mol})$ was added by portions and the vigorous formation of $\mathrm{HBr}$ was observed. The mixture was kept at $60^{\circ} \mathrm{C}$ for $2-4 \mathrm{~h}$ until the PBBB and TBXDB disappeared (controlled by GC and HBr evolution). The reaction mixture was washed three times with water $(3 \times 300 \mathrm{~mL})$ and an aqueous solution of $\mathrm{NaHCO}_{3}$, with $30 \mathrm{~min}$ taken for each washing. The reaction mixture was cooled to $50^{\circ} \mathrm{C}$ and the solid was filtered off and 
dried in an oven at $150{ }^{\circ} \mathrm{C}$ under reduced pressure for $24 \mathrm{~h}$, giving $131.3 \mathrm{~g}$, which corresponded to a $\sim 98 \%$ yield. Based on the chemical analysis, the content of bromine was about $70 \%$. Based on GPC the calculated molecular weight was $M_{\mathrm{n}}=25,000$ and $M_{\mathrm{w}}=385,000$ and polydispersity (PD) was $\mathrm{PD}=15.4, d_{\mathrm{n}} / d_{\mathrm{c}}=0.09$. An FTIR spectrum of T-PBBB-TBXDB is shown in Figure 3 . The major absorption bands attributed to the pentabromobenzene ring are $1318 \mathrm{~cm}^{-1}$ (semicircle stretching), $1061 \mathrm{~cm}^{-1}$ (C-Br stretching) and $552 \mathrm{~cm}^{-1}$ (ring bending). A characteristic band at $1094 \mathrm{~cm}^{-1}(\mathrm{C}-\mathrm{Br}$ stretching) belongs to tetrabromoxylylene dibromide. The bands at $1432 \mathrm{~cm}^{-1}$ (semicircle stretching) and $936 \mathrm{~cm}^{-1}$ (aromatic $\mathrm{C}-\mathrm{H}$ bending) are assigned to substituted toluene. Its chemical structure can be represented as follows.
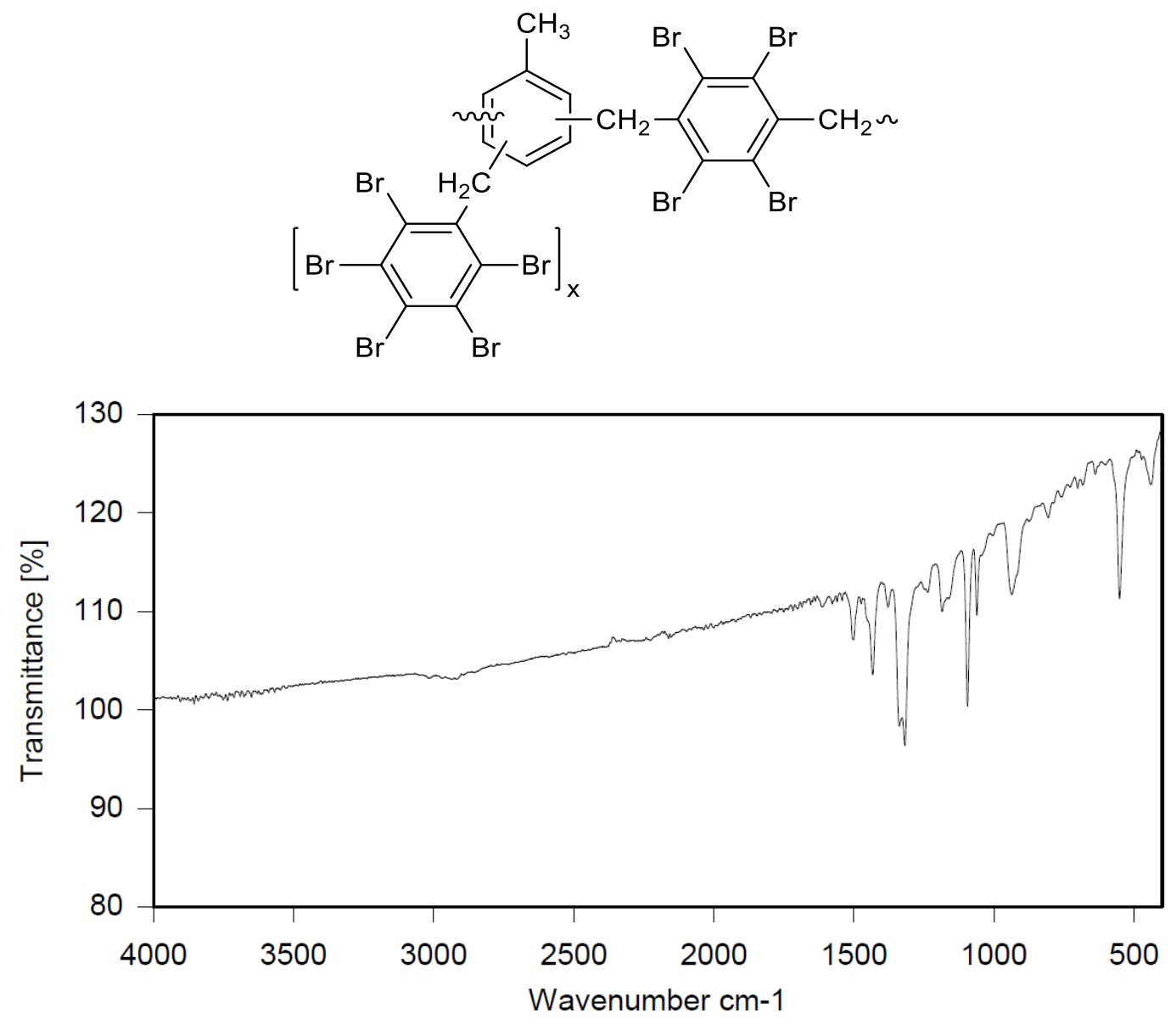

Figure 3. FTIR spectrum of toluene alkylated with $\mathrm{PBBB}$ and tetrabromoxylylene dibromide (T-PBBB-TBXDB).

\subsubsection{Alkylation of Diphenylethane with PBBB and TBXDB (DPE-PBBB-TBXDB)}

Dibromomethane (250 mL), PBBB (113.1 g, $0.2 \mathrm{~mol})$, TBXDB (20.3 g, $0.035 \mathrm{~mol})$, and diphenylethane $(9.1 \mathrm{~g}, 0.05 \mathrm{~mol})$ were placed in a $500 \mathrm{~mL}$ reactor fitted with a mechanical stirrer, thermometer, condenser, $\mathrm{HBr}$ trap, and $\mathrm{N}_{2}$ inlet. The mixture was heated to $60{ }^{\circ} \mathrm{C}$. $\mathrm{AlCl}_{3}(0.8 \mathrm{~g}, 0.006 \mathrm{~mol})$ was added by portions and the vigorous formation of $\mathrm{HBr}$ was observed. The mixture was kept at $60{ }^{\circ} \mathrm{C}$ for 2-4 h until the PBBB and TBXDB disappeared (controlled by GC and $\mathrm{HBr}$ evolution). The reaction mixture was washed three times with water $(3 \times 300 \mathrm{~mL})$ and an aqueous solution of $\mathrm{NaHCO}_{3}$. After washing, the suspension of the product was added dropwise to isopropyl alcohol $(1000 \mathrm{~mL})$, stirred at $20{ }^{\circ} \mathrm{C}$ for $30 \mathrm{~min}$, and the product filtered off. The weight of the product was $114.8 \mathrm{~g}$, which corresponded to a $\sim 94 \%$ yield. The content of bromine was about $75 \%$. Based on GPC the calculated molecular weight was $M_{\mathrm{n}}=19,000$ and $M_{\mathrm{w}}=134,000$ and polydispersity was $\mathrm{PD}=6.9$, $d_{\mathrm{n}} / d_{\mathrm{c}}=0.08$. An FTIR spectrum of DPE-PBBB-TBXDB is shown in Figure 4. The major absorption 
bands attributed to the pentabromobenzene ring are $1318 \mathrm{~cm}^{-1}$ (semicircle stretching), $1061 \mathrm{~cm}^{-1}$ (C-Br stretching) and $552 \mathrm{~cm}^{-1}$ (ring bending). The characteristic band at $1094 \mathrm{~cm}^{-1}$ (C-Br stretching) belongs to tetrabromoxylylene dibromide. The bands at $2981 \mathrm{~cm}^{-1}\left(\mathrm{CH}_{2}\right.$ stretching), $1500 \mathrm{~cm}^{-1}$ and $1432 \mathrm{~cm}^{-1}$ (semicircle stretching) and $940 \mathrm{~cm}^{-1}$ (aromatic C-H bending) are assigned to substituted diphenylethane. The following structure was assigned to this product.
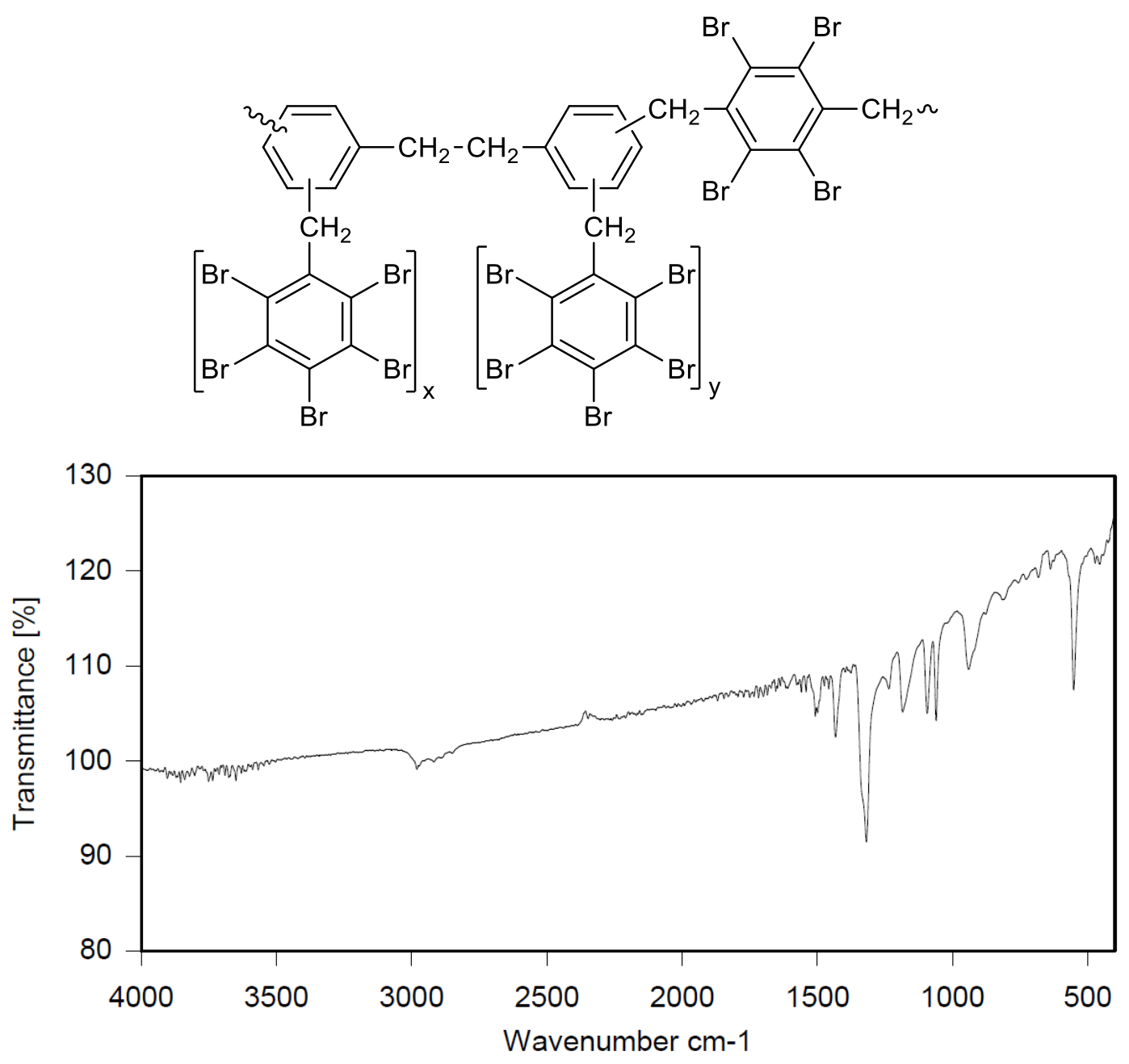

Figure 4. FTIR spectrum of diphenylethane alkylated with PBBB and TBXDB (DPE-PBBB-TBXDB).

\subsubsection{Alkylation of PPE with PBBB (PPE-PBBB)}

Polyphenylene ether oligomer (30 g), PBBB (366.4 g), and dibromomethane (700 mL) were placed in a $1 \mathrm{~L}$ reactor fitted with a mechanical stirrer, thermometer, condenser, $\mathrm{HBr}$ trap, and $\mathrm{N}_{2}$ inlet. The mixture was heated to $70{ }^{\circ} \mathrm{C}$ and $\mathrm{AlCl}_{3}(3.5 \mathrm{~g})$ was added by portions. The mixture was stirred at $90{ }^{\circ} \mathrm{C}$ until the PBBB disappeared $(5-6 \mathrm{~h})$. The reaction mixture was washed at $50{ }^{\circ} \mathrm{C}$ with water $(250 \mathrm{~mL})$ and sodium bisulfite $(2.5 \mathrm{~mL}, \sim 28 \%)$, water $(250 \mathrm{~mL}), 5 \% \mathrm{Na}_{2} \mathrm{CO}_{3}(250 \mathrm{~mL})$, and water (250 mL), with $20 \mathrm{~min}$ taken for each washing. The solvent $(\sim 150 \mathrm{~mL})$ was evaporated under reduced pressure. The remainder, heated at $40-50{ }^{\circ} \mathrm{C}$, was added dropwise to isopropyl alcohol $(450 \mathrm{~mL})$ at $50^{\circ} \mathrm{C}$, over $1 \mathrm{~h}$, under vigorous stirring. The mixture was stirred at $50^{\circ} \mathrm{C}$ for $1 \mathrm{~h}$ and then cooled to $18^{\circ} \mathrm{C}$. The solid was filtered off and washed with isopropyl alcohol $(150 \mathrm{~mL})$ on the filter. The solid was dried in the oven at $105^{\circ} \mathrm{C}$, and at $150{ }^{\circ} \mathrm{C}$ under reduced pressure, for 3 and $7 \mathrm{~h}$ respectively, to give a white powder product ( $318 \mathrm{~g}$, corresponding to $\sim 92 \%$ yield, based on PBBB). The content of bromine was about $75 \%$, which corresponds to about 2.1 PBBB group per one phenylene ether unit. The estimated molecular weight is $M_{\mathrm{w}}=6,200$. An FTIR spectrum of PPE-PBBB is shown in Figure 5. The major absorption bands attributed to the pentabromobenzene ring are $1317 \mathrm{~cm}^{-1}$ 
(semicircle stretching), $1061 \mathrm{~cm}^{-1}$ (C-Br stretching), and $553 \mathrm{~cm}^{-1}$ (ring bending). The bands at $1432 \mathrm{~cm}^{-1}$ (semicircle stretching) and $944 \mathrm{~cm}^{-1}$ (aromatic $\mathrm{C}-\mathrm{H}$ bending) can be assigned to substituted polyphenylene ether. The chemical structure of PPE-PBBB can be represented as follows.<smiles>COc1ccc(Cc2c(Br)c(Br)c(Br)c(Br)c2Br)cc1</smiles>

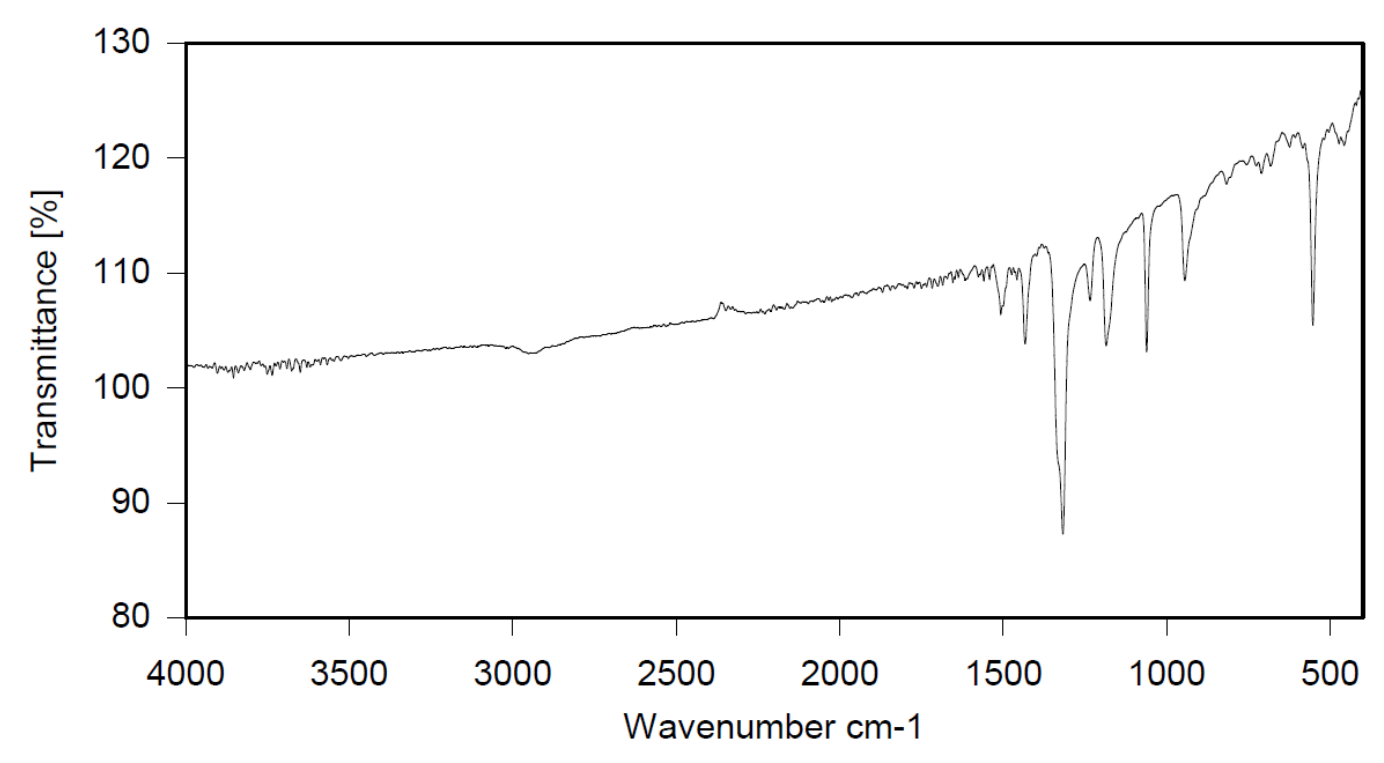

Figure 5. FTIR spectrum of polyphenylene ether alkylated with PBBB (PPE-PBBB).

\subsubsection{Alkylation of PS with PBBB (PS-PBBB)}

Dibromomethane $(1.8 \mathrm{~L})$ and polystyrene $(104.15 \mathrm{~g})$ were placed in a $2 \mathrm{~L}$ reactor fitted with a mechanical stirrer, thermometer, condenser, $\mathrm{HBr}$ trap, and $\mathrm{N}_{2}$ inlet. The mixture was heated to $66{ }^{\circ} \mathrm{C}$ to give a clear solution. PBBB $(565.5 \mathrm{~g})$ was then dissolved in the solution. $\mathrm{AlCl}_{3}(3.1 \mathrm{~g})$ and $\mathrm{SnCl}_{4}(4.8 \mathrm{~g})$ were added and the mixture was heated to $84{ }^{\circ} \mathrm{C}$, after which the vigorous evolution of $\mathrm{HBr}$ started. The mixture was heated at $80^{\circ} \mathrm{C}$ for about $6 \mathrm{~h}$ until the PBBB disappeared (by GC and HPLC). The reaction mixture was washed three times; the mixture was washed with water $(1.5 \mathrm{~L})$, saturated $\mathrm{NaHCO}_{3}$ solution $(1.5 \mathrm{~L})$ to give $\mathrm{pH}=7$, and again with water $(1.5 \mathrm{~L})$, with 30 min taken for each washing. After this, the reaction mixture was added dropwise to acetone $(6 \mathrm{~L})$ to induce precipitation. The reaction mixture was cooled to $20^{\circ} \mathrm{C}$ and the solid was filtered off and dried in an oven at $105^{\circ} \mathrm{C}$ under reduced pressure for $12 \mathrm{~h}$ to give $509 \mathrm{~g}$, which corresponded to an $\sim 86 \%$ yield, based on PBBB. According to elemental analysis, the content of bromine was about $68 \%$, corresponding to about one PBBB molecule per aromatic ring, as shown in the structure below. Based on GPC, the calculated molecular weight was $M_{n}=19,300$ and $M_{\mathrm{w}}=40,100$ and polydispersity was PD $=2.1$. An FTIR spectrum of PS-PBBB is shown in Figure 6. The major absorption bands attributed to the pentabromobenzene ring are $1318 \mathrm{~cm}^{-1}$ (semicircle stretching), $1060 \mathrm{~cm}^{-1}$ (C-Br stretching) and $552 \mathrm{~cm}^{-1}$ (ring bending). The bands at $2981 \mathrm{~cm}^{-1}\left(\mathrm{CH}_{2}\right.$ stretching), $1499 \mathrm{~cm}^{-1}$ and 
$1432 \mathrm{~cm}^{-1}$ (semicircle stretching), and $941 \mathrm{~cm}^{-1}$ (aromatic $\mathrm{C}-\mathrm{H}$ bending) can be assigned to substituted polystyrene. The chemical structure of PS-PBBB can be represented as follows.


Figure 6. FTIR spectrum of polystyrene alkylated with PBBB (PS-PBBB).

\section{Results and Discussion}

\subsection{Thermogravimetry}

TGA curves of two flame retardants made by alkylation with TBBB of toluene and diphenylethane are shown in Figure $7 \mathrm{a}, \mathrm{b}$. It is noticeable that degradation starts at about $370-375{ }^{\circ} \mathrm{C}$ and initially proceeds very quickly with a sharp maximum in the DTG curve. The second step of decomposition is much slower, and it extends all the way up to $600-650^{\circ} \mathrm{C}$. Eventually, the rate of the decomposition slows down at $650-700{ }^{\circ} \mathrm{C}$ and both flame retardants leave about $20 \%$ of solid residue behind. Since both T-TBBB and DPE-TBBB contain about $75 \% \mathrm{Br}$ it is logical to assume that the first and the second steps of weight loss are associated with elimination of bromine along with some aromatic fragments. The TGA of two polymeric flame retardants made by alkylation of toluene and diphenylethane with TBBB and TBXDP are shown in Figure 7c,d. Performance of T-PBBB-TBXDP is very similar to that of T-TBBB (Figure 7a) but T-PBBB-TBXDP leaves higher solid residues of $24 \%$. On the other hand, DPE-PBBB-TBXDP shows a more complex decomposition pattern with the shoulders on the DTG curve before and after the maximum weight loss. Nevertheless, the main pattern remains the same with a relatively fast debromination followed by a slower and more prolonged debromination. Finally, the TGA of the oligomer (PPE) and true polymer (PS) alkylated with TBBA are shown in Figure 7e,f. PPE-TBBB shows very fast initial decomposition with relatively low weight loss of only about $20 \%$, which is followed by a much slower and prolonged debromination. By contrast, PS-TBBB has a slow initial decomposition step of about $50 \%$, which is followed by an even slower step. 


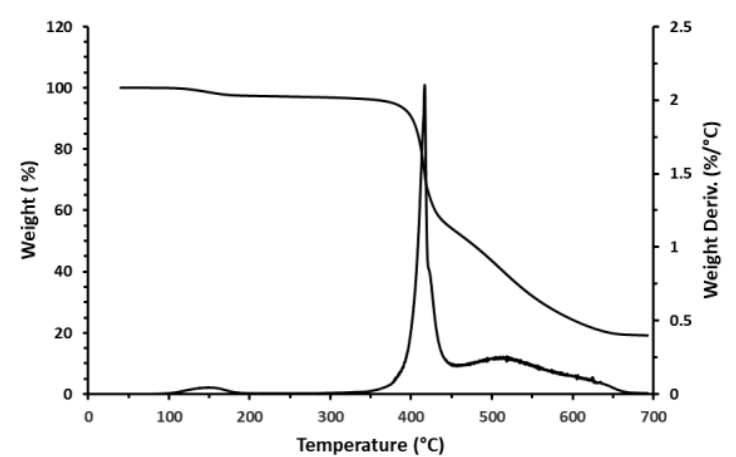

(a)

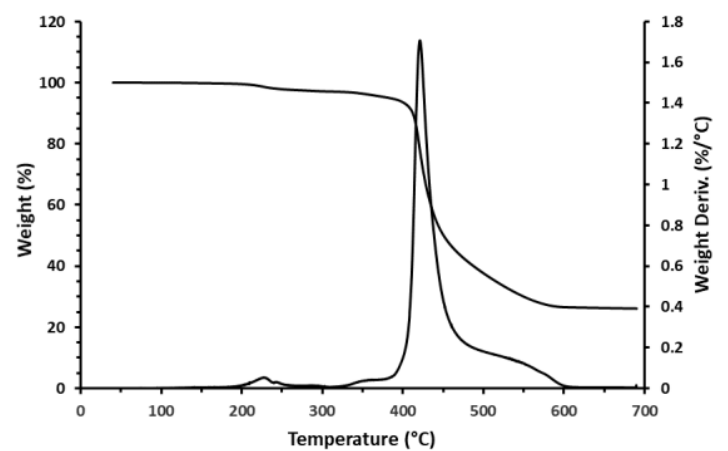

(c)

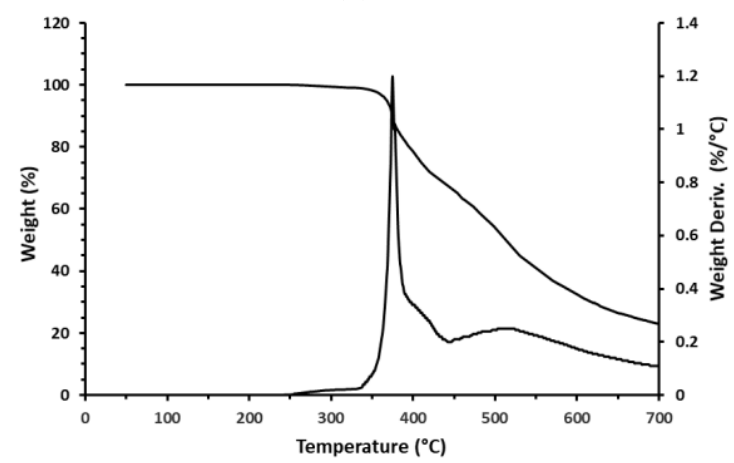

(e)

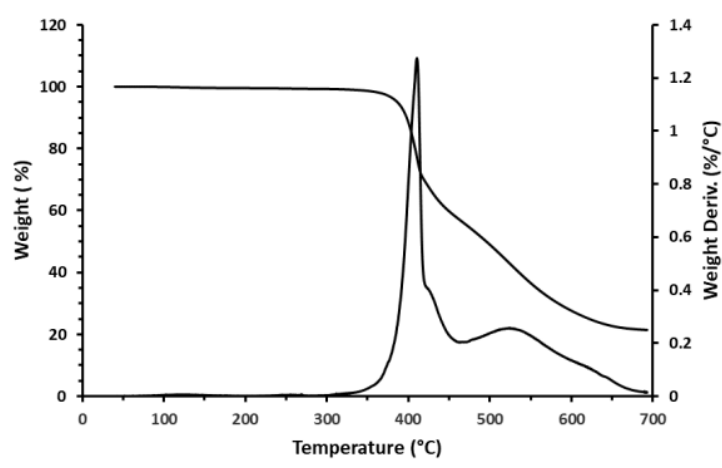

(b)



(d)

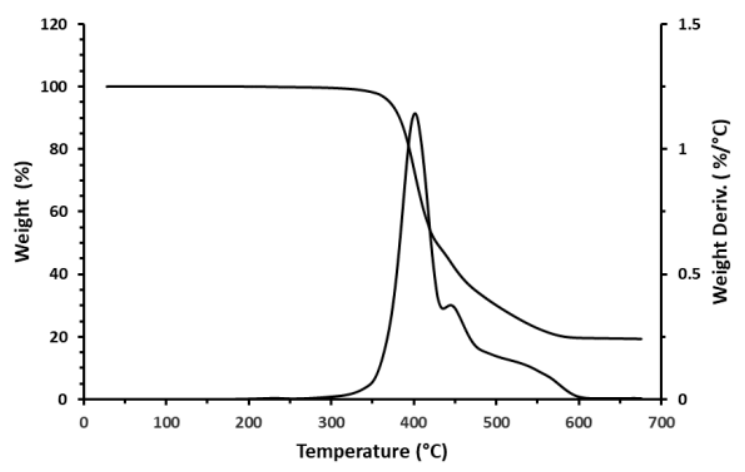

(f)

Figure 7. Thermogravimetric weight loss (TGA) and the rate of weight loss (DTG) of brominated flame retardants. (a) T-PBBB; (b) DBE-PBBB; (c) T-PBBB-TBXDP; (d) DPE-PBBB-TBXDP; (e) PPE-PBBB; (f) PS-PBBB.

Table 2 summarizes TGA data in terms of the temperature of initial weight loss $\left(T_{5 \%}\right)$, main step of weight loss (maximum rate of weight loss $\left(T_{\max }\right)$, approximate end of the first fast step $\left(T_{\text {end }}\right)$, and approximate weight lost in this step (wt. loss)), and solid residue at $700{ }^{\circ} \mathrm{C}$. It is important to note that all of the newly synthesized polymeric flame retardants had high thermal stability, meaning they are stable enough to be processed even with high melting engineering resins like PA 6.6. Interestingly, the non-polymeric flame retardants and polymeric ones prepared by two different methods showed a similar decomposition pattern which is indicative of similar processes taking place, so we can reasonably speculate that the initial fast decomposition can be probably attributed to the elimination of pendant TBBB groups (dealkylation). It is also reasonable to assume that such fragments volatilize in the flaming conditions and quickly deliver a significant amount of bromine to the gas phase. 
Table 2. TGA data of brominated flame retardants.

\begin{tabular}{|c|c|c|c|c|c|}
\hline \multirow[t]{2}{*}{ Flame Retardant } & \multirow{2}{*}{$\begin{array}{c}\text { Initial Decomposition } \\
T_{5 \%},{ }^{\circ} \mathrm{C}\end{array}$} & \multicolumn{3}{|c|}{ Main Step of Weight Loss } & \multirow{2}{*}{$\begin{array}{c}\text { Solid Residue } \\
\text { Wt. } \%\end{array}$} \\
\hline & & $T_{\max ,}{ }^{\circ} \mathrm{C}$ & $T_{\text {end }}{ }^{\circ} \mathrm{C}$ & Wt. loss, \% & \\
\hline T-PBBB & 370 & 410 & 450 & 35 & 19 \\
\hline DBE-PBBB & 375 & 405 & 455 & 35 & 21 \\
\hline T-PBBB-TBXDP & 375 & 410 & 475 & 55 & 26 \\
\hline DBE-PBBB-TBXDP & 360 & 400 & 480 & 50 & 24 \\
\hline PРE-TBBB & 370 & 375 & 390 & 20 & 23 \\
\hline PS-TBBB & 360 & 410 & 435 & 50 & 19 \\
\hline
\end{tabular}

\subsection{Combustion}

\subsubsection{Polypropylene Copolymer}

Polypropylene and its copolymers find significantly more applications in molded parts compared to other polyolefins [21]. Some of these molded parts need to be flame retarded; examples include electrical parts (wire nuts, lamp sockets, coil bobbins, connectors, wire, and cables), housing of electrical appliances, TV yokes, pipes for water discharge, fibers for textile applications, film, and sheets for roofing [22]. The relatively high fuel content of polypropylene (PP) combined with poor compatibility of common brominated flame retardants makes formulation of flame-retardant PP a significant challenge [23]. In order to reach a UL-94 V-0 rating in polypropylene, about $30-40 \%$ of flame retardant is required compared to $12-25 \%$ flame retardant loading for styrenic polymers or engineering thermoplastics [24]. In many molding applications copolymers of propylene and ethylene are used. These copolymers provide better impact strength but they are even more flammable than standard polypropylene.

Newly synthesized brominated flame retardants were tested in unfilled and talc-filled polypropylene-ethylene copolymer. Their compositions, flammability performance, and physical properties are shown in Table 3. Reference data for non-polymeric commercial flame retardant decabromodiphenylethane (FR-1410) and polymeric commercial flame retardant poly (pentabromobenzylacrylate) (FR-1025) are also shown in the table. FR-1410 has a high bromine content of $82 \%$ and because of this it requires lower loading compared to the new experimental flame retardants. Overall, FR-1410 provides good performance in PP copolymer, but it is not polymeric or a high molecular weight flame retardant. FR-1025 is truly polymeric, but it has a high glass transition temperature and is therefore too stiff for PP. As a result, it has a high heat distortion temperature but poor elongation at break.

Non-polymeric flame retardant DPE-PBBB required a slightly higher loading in terms of bromine content (22 versus 21) compared to FR-1410. DPE-PBBB showed a higher heat distortion temperature compared to FR-1410 whereas other mechanical properties were in line with the commercial benchmark. Polymeric PPE-PBBB required lower bromine loading (19.3 versus 23) compared to FR-1025. All newly synthesized polymeric flame retardants showed significantly better elongation at break compared to FR-1025. In the talc-filled compositions both DPE-PBBB and PS-PBBB showed comparable physical properties to those of FR-1025, but again elongation at break was significantly better. 
Table 3. Flammability performance and physical properties of impact-modified PP. Legend: HDT, heat distortion temperature; MFI, melt flow index.

\begin{tabular}{|c|c|c|c|c|c|c|c|c|c|c|}
\hline * Composition, wt.\% & 1 & 2 & 3 & 4 & 5 & 6 & 7 & 8 & 9 & 10 \\
\hline Flame Retardant & FR-1410 & FR-1025 & DPE-PBBB & DPE-PBBB-TBXDB & PPE-PBBB & PS-PBBB & FR-1025 & DPE-PBBB & FR-1025 & PS-PBBB \\
\hline Impact-modified PP & 68.5 & 54.6 & 56.7 & 54.7 & 54.6 & 59.7 & 51.9 & 53.3 & 50.3 & 49.5 \\
\hline Flame retardant & 25.6 & 32.4 & 29.3 & 30.7 & 30.9 & 28 & 25.4 & 24.0 & 25.3 & 26.1 \\
\hline Talc or talc MB & & & & & & & 15.0 & 15.0 & $16.7(10)$ & $16.7(10)$ \\
\hline Antimony trioxide $\mathrm{MB}$ & 13.1 & 12.8 & 13.8 & 14.4 & 14.4 & 12.1 & 7.5 & 7.5 & 7.5 & 7.5 \\
\hline Br content, $\%$ calculated & 21.0 & 23.0 & 22.0 & 23.0 & 23.0 & 19.3 & 18.0 & 18.0 & 18.0 & 18.0 \\
\hline $\mathrm{Sb}_{2} \mathrm{O}_{3}, \%$ calculated & 10.5 & 11.5 & 11.0 & 11.5 & 11.5 & 9.7 & 6.0 & 6.0 & 6.0 & 6.0 \\
\hline $\mathrm{Br} / \mathrm{Sb}_{2} \mathrm{O}_{3}$ ratio & 2.0 & 2.0 & 2.0 & 2.0 & 2.0 & 2.0 & 3.0 & 3.0 & 3.0 & 3.0 \\
\hline UL-94 rating & $\mathrm{V}-0$ & $\mathrm{~V}-0$ & $\mathrm{~V}-0$ & $\mathrm{~V}-0$ & $\mathrm{~V}-0$ & $\mathrm{~V}-0$ & $\mathrm{~V}-0$ & $\mathrm{~V}-0$ & $\mathrm{~V}-0$ & $\mathrm{~V}-0$ \\
\hline Impact strength $(\mathrm{J} / \mathrm{m})$ & 72 & 31 & 27 & 35 & 32 & 33 & 26 & 28 & 35 & 34 \\
\hline Tensile strength $(\mathrm{MPa})$ & 21.2 & 24.6 & 17.2 & 17.6 & 17.0 & 18.9 & 22.3 & 18.0 & 20.4 & 18.6 \\
\hline Elongation at break (\%) & 127 & 6.1 & 64 & 27 & 102 & 47 & 6.9 & 27 & 27 & 57 \\
\hline Tensile modulus (MPa) & 1550 & 1800 & 1490 & 1660 & 1450 & 1620 & 2080 & 2060 & 2170 & 1790 \\
\hline $\operatorname{HDT}\left({ }^{\circ} \mathrm{C}\right)$ & 55 & 84 & 63 & 58 & 57 & 61 & 77 & 67 & 74 & 61 \\
\hline MFI (g/10 min) & 5.3 & 12.5 & 4.1 & 3.8 & 5.9 & 3.8 & 6.2 & 3.5 & 5.0 & 2.9 \\
\hline
\end{tabular}




\subsubsection{ABS and HIPS}

Polystyrene and its copolymers have the tendency to depolymerize when exposed to fire temperatures and the volatile products are materials of high fuel value, namely, styrene monomer, styrene dimers, and related hydrocarbons such as benzene, lower-alkylbenzenes, and a few percent of oxygen-containing related aromatics [25]. Polystyrenes, unless blended with char formers, form little or no char by themselves [26]. The volatiles burn with copious soot formation. Moreover, while depolymerization is taking place, melt flow and drips also occurr, and the drips may be capable of igniting other flammable objects. For many uses of styrenics, especially electrical equipment, the requirements are to prevent a small source of ignition, such as a hot or sparking wire, from igniting the item, or, if the polymer is ignited, to cause it to self-extinguish quickly. Hence, the UL-94 test is the most common and to achieve a V-0 rating it is recommended to add a small amount of polytetrafluoroethylene (PTFE).

Some newly synthesized flame retardants were tested in ABS and compared with commercial flame retardants FR-1410 and F-3020. The compositions, flammability performance, and physical properties are shown in Table 4. The two commercial products had overall good physical properties but also had some deficiencies. FR-1410 has a low resin flow which limits its application in large and thin wall molded parts, whereas F-3020 shows excellent resin flow but poor elongation at break which makes its molded parts somewhat brittle. With a bromine $/ \mathrm{Sb}_{2} \mathrm{O}_{3}$ ratio of 2.5 the newly synthesized flame retardants show similar flame retardant efficiency as the commercial flame retardants, e.g., they provide a V-0 rating at $10.0 \%$ of bromine in the formulation. Although most of the physical properties were found to be in line with those of commercial flame retardants, the impact strength was somewhat lower. In order to increase the impact strength, the loading of DPE-PBBB was increased to a level of $13 \%$ bromine and PPE-PBBB to a level of $11.5 \%$ and $13 \%$ bromine, but antimony trioxide was significantly decreased to a level of $2.1 \%$ and $1.5 \%$. Although the newly synthesized flame retardants did not display an outstanding performance, they had an overall balance of high flame retardant efficiency and good physical properties.

Table 4. Flammability performance and physical properties of ABS plastic.

\begin{tabular}{lcccccccc}
\hline * Composition, wt. $\%$ & $\mathbf{1}$ & $\mathbf{2}$ & $\mathbf{3}$ & $\mathbf{4}$ & $\mathbf{5}$ & $\mathbf{6}$ & $\mathbf{7}$ & $\mathbf{8}$ \\
\hline \multicolumn{1}{c}{ Flame Retardant } & FR-1410 & $\mathbf{F - 3 0 2 0}$ & $\begin{array}{c}\text { DPE- } \\
\text { PBBB }\end{array}$ & $\begin{array}{c}\text { DPE- } \\
\text { PBBB }\end{array}$ & $\begin{array}{c}\text { DPE-PBBB- } \\
\text { TBXDB }\end{array}$ & $\begin{array}{c}\text { PPE- } \\
\text { PBBB }\end{array}$ & $\begin{array}{c}\text { PPE- } \\
\text { PBBB }\end{array}$ & $\begin{array}{c}\text { PPE- } \\
\text { PBBB }\end{array}$ \\
\hline ABS & 82.5 & 76.8 & 81.4 & 80.4 & 81.4 & 81.4 & 81.7 & 80.5 \\
\hline Flame retardant & 12.2 & 17.9 & 13.3 & 17.4 & 13.3 & 13.3 & 15.3 & 17.3 \\
\hline Antimony trioxide MB & 5.0 & 5.0 & 5.0 & 1.9 & 5.0 & 5.0 & 2.6 & 1.9 \\
\hline Br content, \% calculated & 10.0 & 10.0 & 10.0 & 13.0 & 10.0 & 10 & 11.5 & 13.0 \\
\hline $\mathrm{Sb}_{2} \mathrm{O}_{3}, \%$ calculated & 4.0 & 4.0 & 4.0 & 1.5 & 4.0 & 4.0 & 2.1 & 1.5 \\
\hline Bromine/Sb ${ }_{3}$ ratio & 2.5 & 2.5 & 2.5 & 8.7 & 2.5 & 2.5 & 5.5 & 8.7 \\
\hline UL-94 rating & $\mathrm{V}-0$ & $\mathrm{~V}-0$ & $\mathrm{~V}-0$ & $\mathrm{~V}-0$ & $\mathrm{~V}-0$ & $\mathrm{~V}-0$ & $\mathrm{~V}-0$ & $\mathrm{~V}-0$ \\
\hline Impact strength $(\mathrm{J} / \mathrm{m})$ & 128 & 113 & 71 & 104 & 69 & 92 & 78 & 74 \\
\hline Tensile strength $(\mathrm{MPa})$ & 40 & 43 & 37 & 39 & 38 & 38 & 38 & 37 \\
\hline Elongation at break $(\%)$ & 16 & 3 & 7 & 13 & 11 & 6 & 6 & 6 \\
\hline Tensile modulus $(\mathrm{MPa})$ & 2400 & 2330 & 2330 & 2160 & 2330 & 2080 & 2100 & 2070 \\
\hline HDT $\left({ }^{\circ} \mathrm{C}\right)$ & 78 & 76 & 77 & 78 & 78 & 77 & 78 & 79 \\
\hline MFI (g/10 min) & 8.8 & 22.7 & 15.3 & 11.7 & 13.4 & 12.4 & 12.3 & 10.6 \\
\hline
\end{tabular}

* All formulations contained $0.1 \mathrm{wt} . \%$ PTFE and $0.2 \mathrm{wt} . \%$ Irganox B 225. 
The polymeric product of alkylation of diphenylethane with PBBB and TBXDB (DPE-PBBB-TBXDB) was tested for flammability and physical properties in HIPS. Results are presented in Table 5 with a comparison to commercial F-3014. As it is seen, $10 \%$ bromine and $4.0 \%$ antimony trioxide gave only a V-1 rating for both additives. However, interestingly an increase of bromine content to $11 \%$ and a decrease of antimony trioxide content to $2.1 \%$ resulted in a V-0 rating. A further decrease of antimony trioxide to $1.5 \%$ required a boost in the bromine content to $13 \%$. Reference brominated epoxy polymer F-3014 showed a very similar flame retardant efficiency as DPE-PBBB-TBXDB. In terms of physical properties F-3014 had a higher impact and tensile strength, elongation at break and resin flow (MFI). On the other hand, experimental DPE-PBBB-TBXDP showed a somewhat higher tensile modulus and significantly higher heat distortion temperature (HDT) which is beneficial for some HIPS applications.

Table 5. Flammability performance and physical properties of HIPS.

\begin{tabular}{lcccccc}
\hline \multicolumn{1}{c}{ * Composition, wt. $\%$} & $\mathbf{1}$ & $\mathbf{2}$ & $\mathbf{3}$ & $\mathbf{4}$ & $\mathbf{5}$ & $\mathbf{6}$ \\
\hline Flame Retardant & F-3014 & F-3014 & F-3014 & $\begin{array}{c}\text { DPE-PBBB- } \\
\text { TBXDB }\end{array}$ & $\begin{array}{c}\text { DPE-PBBB- } \\
\text { TBXDB }\end{array}$ & $\begin{array}{c}\text { DPE-PBBB- } \\
\text { TBXDB }\end{array}$ \\
\hline HIPS & 78.0 & 78.8 & 76.1 & 82.2 & 83.3 & 81.5 \\
\hline Flame retardant & 16.7 & 18.3 & 21.7 & 12.5 & 13.8 & 16.3 \\
\hline Antimony trioxide MB & 5.0 & 2.6 & 1.9 & 5.0 & 2.6 & 1.9 \\
\hline Br content, $\%$ calculated & 10 & 11 & 13 & 10 & 11 & 13 \\
\hline Sb ${ }_{2} \mathrm{O}_{3}, \%$ calculated & 4.0 & 2.1 & 1.5 & 4.0 & 2.1 & 1.5 \\
\hline Bromine/Sb ${ }_{2} \mathrm{O}_{3}$ ratio & 2.5 & 5.2 & 8.7 & 2.5 & 5.2 & 8.7 \\
\hline UL-94 rating & $\mathrm{V}-1$ & $\mathrm{~V}-0$ & $\mathrm{~V}-0$ & $\mathrm{~V}-1$ & $\mathrm{~V}-0$ & V-0 \\
\hline Impact strength $(\mathrm{J} / \mathrm{m})$ & 67 & 70 & 67 & 43 & 43 & 38 \\
\hline Tensile strength $(\mathrm{MPa})$ & 26 & 25 & 25 & 24 & 25 & 23 \\
\hline Elongation at break $(\%)$ & 40 & 57 & 47 & 17 & 15 & 11 \\
\hline Tensile modulus $(\mathrm{MPa})$ & 1980 & 1920 & 1910 & 2100 & 2070 & 2050 \\
\hline HDT $\left({ }^{\circ} \mathrm{C}\right)$ & 65 & 66 & 65 & 71 & 72 & 72 \\
\hline MFI (g/10 min) & 14.4 & 13.8 & 14.2 & 4.2 & 4.0 & 4.2 \\
\hline
\end{tabular}

\subsubsection{Polyamide 6.6}

Fire retardancy of aliphatic polyamides is mostly required in electric industries with typical applications in electrical connectors, terminal blocks, small electrical housings, clip fasteners, switch components, wire ties, and many other industrial parts [27]. Among other engineering resins, polyamides are known as materials with relatively high strength, high ductility, excellent resistance to short-term heat exposure, and good resistance to chemical solvents [28]. It is not easy to flame retard polyamides because many FRs cause destabilization (discoloration and reduction in melt viscosity) because of the polymer sensitivity to even low concentration of acids. Another problem encountered with some flame-retarded polyamides is the migration of the additive during processing, water conditioning, or long use of the polymer, which might lead to a loss of flame retardancy.

Newly synthesized brominated flame retardants were tested in glass-filled polyamide 6.6 and compared with commercial brominated polystyrene, FR-803P (Table 6). It is interesting to note that DPE-PBBB required a significantly lower loading of $10 \% \mathrm{Br}$ and $4.8 \% \mathrm{Sb}_{2} \mathrm{O}_{3}$ to achieve a $\mathrm{V}-0$ rating compared to other experimental flame retardants as well as commercial FR-803P. Only the Izod impact strength of commercial FR-803P was somehow higher than the newly synthesized flame retardants. In general, the experimental flame retardants showed a noticeable advantage in the melt flow, which could be related to a lower loading because in general the experimental flame retardants were observed 
to have a higher bromine content $(68-75 \%)$ compared to FR-803P $(66 \%)$. All other properties of commercial FR-803P and the newly synthesized flame retardants were similar.

Table 6. Flammability performance and physical properties of glass-filled polyamide 6.6.

\begin{tabular}{lccccc}
\hline * Composition, wt. $\%$ & $\mathbf{1}$ & $\mathbf{2}$ & $\mathbf{3}$ & $\mathbf{4}$ & $\mathbf{5}$ \\
\hline \multicolumn{1}{c}{ Flame Retardant } & FR-803P & T-PBBB & DPE-PBBB & PPE-PBBB & PS-PBBB \\
\hline PA 6.6 & 43.5 & 46.3 & 51.3 & 45.8 & 44.1 \\
\hline Glass fiber & 30 & 30 & 30 & 30 & 30 \\
\hline Flame retardant & 19.7 & 16.9 & 13.3 & 17.4 & 19.1 \\
\hline Antimony trioxide MB & 6.2 & 6.2 & 4.8 & 6.2 & 6.2 \\
\hline $\mathrm{Br}($ calculated) & 13 & 13 & 10 & 13 & 13 \\
\hline $\mathrm{Sb}{ }_{2} \mathrm{O}_{3}$ (calculated) & 4.8 & 5.0 & 3.8 & 5.0 & 5.0 \\
\hline $\mathrm{Br} / \mathrm{Sb}{ }_{2} \mathrm{O}_{3}$ (calculated) & 2.7 & 2.6 & 2.6 & 2.6 & 2.6 \\
\hline $\mathrm{UL}-94$ rating & $\mathrm{V}-0$ & $\mathrm{~V}-0$ & $\mathrm{~V}-0$ & $\mathrm{~V}-0$ & $\mathrm{~V}-0$ \\
\hline Izod Impact $(\mathrm{J} / \mathrm{m})$ & 111 & 104 & 103 & 104 & 97 \\
\hline Tensile strength $(\mathrm{MPa})$ & 143 & 150 & 150 & 135 & 137 \\
\hline Elongation at break $(\%)$ & 3.3 & 4.2 & 4.7 & 4.3 & 3.5 \\
\hline Tensile modulus $(\mathrm{MPa})$ & 10050 & 10750 & 9950 & 8630 & 10450 \\
\hline HDT $\left({ }^{\circ} \mathrm{C}\right)$ & 225 & 226 & 231 & 228 & 216 \\
\hline MFI $(\mathrm{g} / 10$ min) & 7 & 11 & 29 & 13 & 15 \\
\hline
\end{tabular}

* All formulations contained 0.2 wt.\% Acrawax C, 0.2 wt.\% Irganox 51171, and $0.2 \mathrm{wt} . \%$ Ca-stearate.

\section{Conclusions}

In this work, two new non-polymeric brominated flame retardants were successfully synthesized in one simple step by the alkylation of toluene or diphenylethylene with pentabromobenzyl bromide. Two polymeric brominated flame retardants were synthesized when monofunctional pentabromobenzyl bromide and difunctional tetrabromoxylylene dibromide were applied together to alkylate toluene or diphenylethylene. Finally, two other polymeric flame retardants were synthesized by alkylation of polyphenylene ether or polystyrene with pentabromobenzyl bromide. Chemical analysis showed that the new brominated flame retardants had bromine content in the range $68-75 \%$. All new flame retardants showed good thermal stability in excess of $360{ }^{\circ} \mathrm{C}$ and therefore can be used in commodity resins as well as engineering thermoplastics. The new brominated flame retardants were tested in unfilled and mineral-filled polypropylene copolymer, HIPS, ABS, and glass-filled polyamide 6.6. In terms of efficiency, due to the high bromine content the new flame retardants performed similarly to or better than commercial flame retardants. For example, non-polymeric flame retardant DPE-PBBB performed well in glass-filled polyamide 6.6, where it showed a higher flame retardant efficiency compared to commercial brominated polystyrene. Two polymeric flame retardants DPE-PBBB-TBXDB and PPE-PBBB enabled low antimony V-0 formulations in HIPS and ABS, respectfully. Pentabromobenzyl bromide alkylated polystyrene surprisingly showed better flame retardant efficiency in polypropylene compared to all other newly synthesized flame retardants. The physical properties of the flame-retardant thermoplastics with all new flame retardants were in line with or better than the commercial references.

\section{Patents}

Two patents US 10.336,858 (2 July, 2019) and US 10,472,462 (12 November, 2019), both to Bromine Compounds, resulted from the work reported in this paper. 
Author Contributions: Conceptualization, M.G. and D.Y.; methodology, M.G. and D.Y.; validation, M.Y. and E.E.; investigation, M.Y. and E.E.; resources, M.G. and S.L.; writing-original draft preparation, S.L.; writing一review and editing, S.L.; supervision, M.G.; project administration, M.G. All authors have read and agreed to the published version of the manuscript.

Funding: This research received no external funding

Acknowledgments: The authors are thankful to Marcelo Kallos for the TGA experiments, to Israel Patla for the GPC analysis, for Olga Tobias for FTIR, and to Orly Cohen and Renata Elizarov for synthesis.

Conflicts of Interest: The authors declare no conflict of interest.

\section{References}

1. Lipinski, C.A.; Lombardo, F.; Dominy, B.W.; Feeney, P.J. Experimental and computational approaches to estimate solubility and permeability in drug discovery and development settings. Adv. Drug Deliv. Rev. 2001, 46, 3-26. [CrossRef]

2. Williams, C. Polymeric flame retardants to replace DecaBDE. Speciality Chemicals Magazines, September 2012; 28-30.

3. Mapleston, P. Flame retardants trend to polymerics. Compounding Word, December 2016; 15-30.

4. Borgnes, D.; Rikhein, B. Emission Measurements during Incineration of Waste Containing Bromine; Kjelfireningen Nork Energi Report No. 25391; Nork Energi: Oslo, Norway, 2004.

5. Tange, L.; Drohmann, D. Environmental issues related to end-of-life options of plastics containing brominated flame retardants. Fire Mater. 2004, 28, 403-410. [CrossRef]

6. Tange, L.; Van Houwelingen, J.A.; Peeters, J.R.; Vanegas, P. Recycling of flame retardant plastics from WEEE, technical and environmental challenges. Adv. Prod. Eng. Manag. 2013, 8, 63-144. [CrossRef]

7. Peetersa, J.R.; Vanegas, P.; Tange, L.; Van Houwelingen, J.; Duflou, J.R. Closed loop recycling of plastics containing flame retardants. Resour. Conserv. Recycl. 2014, 84, 35-43. [CrossRef]

8. Imai, T. Comparative recyclability of flame retarded plastics. In Proceedings of the International Fire Safety Conferene, FRCA, San Francisco, CA, USA, 11-14 March 2001; pp. 63-86.

9. Imai, T.; Hamm, S.; Rothenbacher, K.P. Comparison of recyclability of flame retarded plastics. Environ. Sci. Technol. 2003, 37, 652-656. [CrossRef] [PubMed]

10. Levchik, S.; Georlette, P.; Bar-Yaakov, Y.; Finberg, I.; Hirschsohn, Y. Polymeric flame retardants. In Proceedings of the Conference Recent Advances in Flame Retardancy of Polymeric Materials, BCC, Stamford, CT, USA, 24-26 May 2010.

11. King, B.; Stobby, W.G.; Murray, D.J.; Worku, A.Z.; Beulich, I.; Tinetti, S.M.; Hahn, S.F.; Drumright, R.E. Brominated Butadiene/Vinyl Aromatic Copolymers, Blends of Such Copolymers with Vinylaromatic Polymer, and Foams Fromed from Such Blends. European Patent 1,957,544, 10 January 2010. to Dow Chemicals.

12. Beach, M.; King, B.; Beulich, I.; Morgan, T.; Stobby, B.; Kram, S.; Hull, J.; Lukas, C.; Kiefer, J.; Leng, R.; et al. New class of brominated polymeric flame retardants. In Proceedings of the Conference on Recent Advances in Flame Retardancy of Polymeric Materials, BCC, Stamford, CT, USA, 23-25 May 2011.

13. Layman, W.J.; Kolich, C.H.; Mack, A.G.; Anderson, S.A.; McCarney, J.P.; Morice, J.; Ge, Z.; Wang, J. Bromination of Telomer Mixtures Derived from Toluene and Styrene. U.S. Patent 8,642,821, 4 February 2014. to Albemarle.

14. Timberlake, L.D.; Fielding, W.R.; Mathur, S.; Hanson, M.V. Brominated Flame Retardant. U.S. Patent 7,550,551, 23 June 2009. to Chemtura.

15. King, B.A.; Worku, A.; Stobby, W.G. Brominated Polymers as Flame Additives and Polymer Systems Containing Same. European Patent 2,247,664, 2 June 2012. to Dow Chemicals.

16. Yashiki, K.; Sudo, A. Bromine-Containing Polymers and Methods for Producing the Same. U.S. Patent 10,442,876, 15 October 2019. to Manac.

17. Campbell, E.J.; Czaplewski, S.K.; Kobilka, B.M.; Wertz, J.T. Flame Retardant Polycaprolactone. U.S. Patent 10,308,875, 4 June 2019. to IBM.

18. Peled, M.; Kornberg, N. Process for the Preparation of Poly-(halobenzyl acrylate). U.S. Patent 6,028,156, 22 February 2000. to Bromine Compounds.

19. Kornberg, N.; Adda, M.; Peled, M. Synthesis of Polyhalogenated Halomethyl Compounds. U.S. Patent 7,601,774, 13 October 2009. to Bromine Compounds. 
20. Colthup, N.R.; Daly, L.H.; Wiberly, S.E. Introduction to Infrared and Raman Spectroscopy, 3rd ed.; Academic Press: Boston, MA, USA, 1990.

21. Lieberman, R.; Stewart, C. Polypropylene Polymers. In Encyclopedia of Polymer Science and Technology; Wiley: Hoboken, NJ, USA, 2002; Volume 11, pp. 287-358.

22. Bar Yaakov, Y.; Utevski, L.; Reyes, J.; Georlette, P.; Bron, S.; Lopez-Cuesta, J.M. Existing fire retardant systems for polypropylene and its copolymers and new developments. In Flame Retardants 2000; Interscience Communications: London, UK, 2000; pp. 87-97.

23. Hini, S.; Reznick, G.; Bar Yaakov, Y.; Georlette, P.; Geran, T.; Squires, G. A new dimension in fire safety. In Proceedings of the Conference on Recent Advances in Flame Retardancy of Polymeric Materials, Stamford, CT, USA, 3-5 June 2002.

24. Georlette, P.; Simons, J.; Costa, L. Halogen-containing fire-retardant compounds. In Fire Retardancy of Polymeric Materials; Grand, A.F., Wilkie, C.A., Eds.; Marcel Dekker: New York, NY, USA, 2000; pp. 246-284.

25. Horak, Z.; Rosik, L. Modification of flammability characteristics. In Styrene-Based Plastics and Their Modification; Svec, P., Rosik, L., Horak, Z., Vecerka, F., Eds.; Ellis Horwood: New York, NY, USA, 1990; pp. 277-299.

26. Hirschler, M.M. Chemical Aspects of Thermal Decomposition of Polymeric Materials. In Fire Retardancy of Polymeric Materials; Grand, A.F., Wilkie, C.A., Eds.; Marcel Dekker: New York, NY, USA, 2000; pp. 27-79.

27. Hochberg, A.; Glogovsky, J. Key properties of FR engineering thermoplastics for demanding applications. In Proceedings of the Society of Plastic Engineers ANTEC Conference, Boston, MA, USA, 7-11 May 1995; pp. 3518-3526.

28. Crosby, J.M.; Talley, K.L. Designing in reinforced flame-retardant plastics. Mod. Plast. 1982, 59, 66-70.

(C) 2020 by the authors. Licensee MDPI, Basel, Switzerland. This article is an open access article distributed under the terms and conditions of the Creative Commons Attribution (CC BY) license (http://creativecommons.org/licenses/by/4.0/). 